\title{
CPD: preparing for the 2014 audit cycle
}

\begin{abstract}
Continuing professional development (CPD) is an expected, continuous activity for all registered ODPs, moreover any registrant with 2 years or more on the register could be selected for audit and have to demonstrate their CPD activities. The profession is approaching its fourth round of CPD audits this year. While ODPs are inherently good at adapting to evolving situations in a professional way, in line with the needs of service users and the profession, they often struggle to formally demonstrate their CPD activity. This article aims to remind registrants of their mandatory requirements for completing and recording CPD activity, and uses a case study approach to explore what CPD is and how it can be easily demonstrated
\end{abstract}

KEY WORDS: Continuing professional development / Standards / Service users / Lifelong learning / Profile
Mick Harper, Principal Lecturer and Technology Advanced Learning Lead; Penny Joyce, Principal Lecturer and Professional Practice Lead, School of Health Sciences and Social Work, University of Portsmouth project report (Department of Health, 2002).

For all 16 professions registered by HCPC CPD is a auditable requirement. For ODPs this came into force in July 2006, and is directly linked to continuing registration. Article 19.4 of the Health Profession Order 2001 allows HCPC under legislation to ask for evidence of an individual's CPD in order for them to stay on the register, so it is not 'optional' for anyone. The audit timetable has been set by HCPC and the next audit for ODPs-covering activity for November 2012 to September 2014-will take place in the re-registration window of 1 September to 30 November 2014, so the clock is ticking!

ODPs are inherently good at adapting to evolving situations in a professional way. They are hard wired to be inquisitive and resourceful to the needs of others and can improvise and adapt working practices to suit their working environment and needs of service users (a term that refers simply to whoever is receiving their professional expertise: patients, families, carers, work colleagues, students). However, mention of the term $\mathrm{CPD}$ can strike fear in the most hardened professional, probably because historically it has been a confusing term.
ODPs previously did not have to formally demonstrate their evolving knowledge and application to practice, it was an implicit activity (they generally did, but passively) and they certainly never had to prove it or make it an explicit activity. It is probably the latter that is the fear factor for many registrants.

\section{The context of CPD for ODPs}

The medical community in the UK introduced CPD as a descriptive term in 1993 when a governmental standing committee formally proposed the term in relation to postgraduate medical and dental education (Ellis and Nolan, 1994). This was in recognition of the fact that the needs for these professionals to continue to learn was more complex than was first thought. There had to be a distinction between normal work activity and changing by learning within an evolving profession. Changes, such as new practices, procedures or skills to underpin clinical service developments and recognition that research evolved practice, were transforming. Audit and regulation to improve patient outcome, a workforce that was becoming more mobile and demanding in their individual career 'wants' and the introduction of information technology; as well as the explosion of equipment development shaped the professional landscape that is known today (Coeffield, 2000), this is what CPD is all about.

Consider assisting an anaesthetist 15 years ago: the drugs used were different, pain relief was managed differently, the operating table and anaesthetic machine would be very dated by today's standards, the patient profile was different and probably even the type of surgery performed. ODPs have had to change their practice, learn new equipment, respond to service user needs and update their skills and knowledge. This is lifelong learning encompassing CPD, the ability to continuously professionally develop. It is something that ODPs do all of the time, but what the profession generally fails to do is formally recognise, or record, that this is being done.

Currently ODPs have to comply with the statutory body's standards for CPD (HCPC, 2012 ). 
Box 1. Health and Care Professions Council (HCPC) standards for continuing professional development (CPD) that registrants must comply with

Standard 1: Maintain a continuous, up-to-date and accurate record of their CPD activities

Standard 2: Demonstrate that their CPD activities are a mixture of learning activities relevant to current or future practice

Standard 3: Seek to ensure that their CPD has contributed to the quality of their practice and service delivery

Standard 4: Seek to ensure that their CPD benefits the service user

Standard 5: On request, present a written profile (which must be their own work and supported by evidence) explaining how they have met the standards for CPD

Source: Health and Care Professions Council (2012)

There are five standards for CPD and although a registrant may not to be called for audit immediately after their first registration (there has to be a 2-year cycle so that the person can generate and demonstrate CPD activity) they must demonstrate and declare that they continue to meet the standards biennially. The standards are outlined in Box 1 and each standard shall be contextualised further in order to show how ODPs can meet their statutory responsibilities.

In relation to these five standards, Box 2 provides a case study highlighting these principles in action. Hopefully ODPs will find some similarities between themselves and 'Bob Jervis' (a fictional character), in either their current role or a role that they aspire to do in the future. The case study should allow the reader to decide two things:

- What are Bob's normal work activities i.e. the expected tasks that he performs to adhere to his scope of practice and standards of proficiency?

- How many CPD activities or opportunities can be identified?

It may be possible to identify that Bob's normal

\section{Many ODPs think that} maintaining a log of cases that they scrub, recover or assist for in anaesthesia is CPD. It is not; they are work activity unless there is something different about a particular case that makes you pause and reflect, or generates a learning event. work role is that of a scrub practitioner with occasional anaesthetics and recovery duties. As part of that normal work role there is a new type of case he must learn (quite normal), apart from that he has an appraisal (again, quite normal) and he has to undertake an annual update on manual handling. Given this description of Bob Jervis, in fact none of what is written could be classed as CPD on its own. All of what is written is generally quite normal work activity. However, there are lots of things that Bob could use for CPD if he expanded on each of the tasks he has to do and made them meaningful. Taking a look at each of the CPD opportunities from Bob's normal day:

- Bob studied the new case that he is to do; he read the manual (self-directed study)

- Bob has prepared his appraisal document, hopefully with some reflection on his current role and his future aspirations (identification of professional strengths and needs)

- Bob is going to have a manual handling update (professional updating)

- Mentorship qualification (formal course completion)
- Knowledge transfer (teaching others)

- Assistant coach (developing teamwork skills and communication)

- Reading departmental literature and emails (helps to develop skills towards aspirations of management)

- Consideration of formal course (planning lifelong learning).

The simple thing is that virtually anything can be used for CPD, but there are a few rules. The first is that regardless of standards or models of conducting $\mathrm{CPD}$, it has to be meaningful and useful, both to an individual and to service users. Work activity is just that, work activity. Many ODPs think that maintaining a log of cases that they scrub, recover or assist for in anaesthesia is CPD. It is not; they are work activities, unless there is something different about a particular case that makes someone pause and reflect, or generates a learning event. In Bob's case, for example, CPD was not the new case that he was to scrub for, but the fact that he had undertaken some self-directed learning in order to increase his knowledge and understanding about what he would have to do.

Any registrant can conduct $\mathrm{CPD}$ in many ways, obvious CPD activities include work-based learning, which is inherent in most registrant's daily lives; formal courses (mentorship in Bob's case) that seek to raise knowledge or skill; audit or review of practice; teaching or mentoring (telling colleagues about the new case); and instigating change management. Some other more abstract activities include watching television, reading a newspaper or having a conversation.

The point is, if a health professional can demonstrate that the activities they undertake meet the regulatory and employing organisations'

\section{Box 2. Case study-Bob Jervis, the operating department practitioner (ODP)}

Bob Jervis is an average ODP. He spends most of his working life in trauma orthopaedics as a scrub practitioner and he enjoys this role. When required he spends time working in anaesthetics (usually a couple of lists a month) and maintains his recovery skills and knowledge by recovering his own patients when on call (usually twice a month). Today is Wednesday and Bob is quite excited because there is a new type of knee replacement that he is going to scrub for today, he read the manual relating to the set and procedure last night and feels quite confident about the case. But he has to wait until 1 pm for this new case - first Bob has to have his annual appraisal, and then he is booked onto a manual handling update at $11 \mathrm{am}$, which he is dreading (and let's face it, who doesn't?). Bob looks forward to his appraisal because although he has only been qualified for three years he wants to progress in his role. Bob has prepared his appraisal documentation and has included the certificate for his mentorship course that he recently completed at his local university. Bob thinks that he is a charismatic teacher and this shall be proved later when he gives an update about the new knee replacement to a few interested colleagues and students. Outside work Bob has quite a normal life, he enjoys working with his local amateur football team and is learning how to be an assistant coach. Bob's overall aspirations are in perioperative management, though he knows that it may take many years to realise that aspiration! In the meantime he keeps abreast of his departmental managerial updates through reading minutes of the meetings that are e-mailed to him. He may even enroll on a leadership course to help him to realise his aspirations 
standards - by selecting a range of CPD activities - and they can identify how those activities make them better and enhance service delivery, then that is acceptable as CPD. This policy is not without its problems. Some registrants struggle with two areas, the first is to decide which activities to document or include as CPD activity and the second is how those activities have improved the self, department or, crucially, service delivery.

\section{Recording your CPD activity}

Hopefully the reader will now have a broad understanding of what CPD is, an idea of the value of CPD and know that it must (and should) be part of their lifelong learning and normal working life and career. The standards that HCPC has set are fair, very achievable and clear. In addition these standards have been consulted on widely among professional groups and employers to ensure that they are fit for purpose i.e. they do what they should.

For some, this will be the first time that any CPD standards have been introduced. The standards in Box 1 are the current standards that ODPs must comply with and demonstrate in order to be able to use the protected title RODP and work as an ODP. The first thing to do is ensure that an ODP has a complete list of all of the CPD activity that has been undertaken. The list should only go back for the last 2 years.

The record of CPD activities should be continuous and in reality should be updated on a 2-week or monthly basis to maintain accuracy. The difficulty here is that if the record is not completed using a 'little and often' approach, a person is likely to forget or omit pieces of CPD activity that demonstrate continuity in their approach. The example in Table 1 is a shortened version of what a real record may look like. It would be very unlikely that only eight CPD activities were conducted in 2 years.

Many complex applications or data management software exist to manage such a record, but the simplest method is to have a page in a book for each month and add activities as they are formally attended, or informal activities that result in CPD. The best method of maintaining a CPD record should include the date of the activity, the type of activity, the evidence that the registrant has to support that the activity was undertaken and notes on relevance to current or future (intended) job roles. Table 1 offers a simple example of a CPD record. The HCPC has its own, which is sent to those registrants selected for audit, but an ODP may design their own and use in any for-

\begin{tabular}{|c|c|c|c|c|}
\hline Date & Activity & $\begin{array}{l}\text { Type of CPD } \\
\text { activity }\end{array}$ & Evidence & Notes \\
\hline 01/09/2012 & $\begin{array}{l}\text { Manual handling } \\
\text { update }\end{array}$ & Mandatory training & Certificate & $\begin{array}{l}\text { Update of hover } \\
\text { mattress }\end{array}$ \\
\hline $10 / 10 / 2012$ & Mentorship course & Formal course & Certificate & $\begin{array}{l}\text { Supporting } \\
\text { students learning }\end{array}$ \\
\hline $12 / 02 / 2013$ & $\begin{array}{l}\text { Conversation with } \\
\text { new anaesthetist }\end{array}$ & $\begin{array}{l}\text { Work-based } \\
\text { learning }\end{array}$ & Reflection & $\begin{array}{l}\text { Discussion around } \\
\text { preferences }\end{array}$ \\
\hline $15 / 04 / 2013$ & $\begin{array}{l}\text { Began health and } \\
\text { safety study }\end{array}$ & Formal learning & $\begin{array}{l}\text { Enrolment } \\
\text { documentation }\end{array}$ & $\begin{array}{l}\text { Supporting } \\
\text { departmental } \\
\text { needs }\end{array}$ \\
\hline 06/06/2013 & Care conference & Informal learning & $\begin{array}{l}\text { Conference } \\
\text { schedule and e } \\
\text { mail confirming } \\
\text { attendance }\end{array}$ & $\begin{array}{l}\text { Learning new } \\
\text { warming } \\
\text { techniques and } \\
\text { guidelines }\end{array}$ \\
\hline $24 / 09 / 2013$ & $\begin{array}{l}\text { Advanced life } \\
\text { support course }\end{array}$ & Formal learning & Certificate & $\begin{array}{l}\text { Knowledge } \\
\text { transfer to } \\
\text { students' and } \\
\text { colleagues }\end{array}$ \\
\hline 01/01/2014 & Reading articles & $\begin{array}{l}\text { Self-directed } \\
\text { learning }\end{array}$ & Article (annotated) & $\begin{array}{l}\text { Dangers of } \\
\text { vancomycin- } \\
\text { resistant } \\
\text { Staphylococcus } \\
\text { aureus }\end{array}$ \\
\hline $29 / 04 / 2014$ & $\begin{array}{l}\text { Student } \\
\text { assessment }\end{array}$ & $\begin{array}{l}\text { Work-based } \\
\text { learning }\end{array}$ & $\begin{array}{l}\text { Student } \\
\text { assessment } \\
\text { document } \\
\text { (anonymous) }\end{array}$ & $\begin{array}{l}\text { Conducted scrub } \\
\text { teaching and } \\
\text { assessment }\end{array}$ \\
\hline
\end{tabular}

mat, so long as it is clear.

This record (and its accuracy) is critical for two main reasons. The first reason is that it demonstrates that the registrant has recorded CPD activities and sought to organise each activity by listing evidence and type of activity (meets HCPC standards 1 and 2). The second reason is that the registrant can use this record to negotiate development opportunities with their line managers during review or performance meetings. An employer could review this record and help decide what the employee's strengths, interests and limitations are within the context of the organisation or department, and identify possible future developmental activity for the individual that can then be formally managed. If an individual does not have a list like this tucked into a box file or a carrier bag or on their desktop then it is strongly recommended that they begin one, as this forms the essence of or foundation for CPD—get this right and the rest is easy.

The lists below demonstrate that there are many ways of supporting CPD activity and these can be work-based or not, the key here is to make sure that the person undertakes learning and activities in lots of different ways that are meaningful to them, as part of their lifelong learning. This is not usually a problem for ODPs because of the work dynamic. It also means that $\mathrm{CPD}$ activity is meaningful and demonstrable, regardless of whether the registrant is working full- or part-time, in teaching, management or seconded to a new role, or if the registrant has flexible hours such as self-employed or agency staff.

\section{Documenting your CPD evidence: the CPD profile}

It is inevitable that at some point an ODP will have to show off' their CPD activity. That may be as part of a demonstration to others to assist them in their own CPD. It may be to a line manager as part of the appraisal process or to justify investment in them as an indivdual, for further development or courses as part of the organisations' needs. It may be to the HCPC for the purpose of audit. If selected for audit, a profile will need to be submitted, if using the template that the HCPC provides for this, sections are less likely to be missed out. 
Box 3. A few examples of different types of CPD activities

- Studying for a qualification

- Mandatory training

- Advanced learning (advanced life support)

- Achieving competency on new equipment

- Coaching

- Supporting learners

- Representing your department on committees

- Auditing

- Developing policy

- Project management

- Reporting on serious untoward incidents

- Active participation in your professional

body activities

- Teaching or examining

- Conference presentations

- Reading journals

- Evaluating research

- Watching television

- Public service

- Knowledge transfer

To put this in the specific context of the HCPC audit process, an example of the mentorship course from Table 1 will be demonstrated against the HCPC CPD standards.

The profile has five sections to it:

- Profile section 1 is an individual's profession and unique CPD number

- Profile section 2 is a brief summary of their current and aspirant role if appropriate. This allows the CPD assessors to get a snapshot of their day-to-day role and, if appropriate, the role they aspire to reach in order to make sense of their CPD in context. Therefore, it is important to ensure mentoring students features as part of a health professional's current or future role

- Profile section 3 is a personal statement, which evaluates CPD (mentorship course) in relation to standards 3 and 4-do not underestimate this section

- Profile section 4 is the contents list of evidence submitted in support of the selected CPD being discussed (mentorship course and two or three other examples)

- Profile section 5 is the complete list of all CPD activities for the whole audit period (October 2012-November 2014) - although this is the last section it should be a starting point. Therefore, using the example of mentorship as one of a range of CPD activities (remember an individual needs to demonstrate a range of activities spanning the 2-year audit cycle), a profile would include the following:

Standard 1: maintain a continuous, up-to-date and accurate record of CPD activities. This will be a list of all CPD activities during the audit period (section 5). Mentorship CPD must be in this list Standard 2: demonstrate that CPD activities are a mixture of learning activities relevant to current or future practice. Mentorship CPD could include a number of activities, for example formal learning if an individual attended a course, had an online workshop to update, if student feedback was given on their performance as a mentor, reading, peer evaluation or appraisal (sections 2, 4 and 5).

Standard 3: seek to ensure that CPD has contributed to the quality of practice and service delivery. A person needs to discuss here how mentorship CPD has made them a better mentor. It may be that they are not yet a mentor, but are planning to be. Therefore, a mentorship course, for example, may be part of the plan to achieve this goal. It might be essential updating in terms of the student's programme requirements, or time management or giving feedback were areas in need of development (section 3).

Standard 4: seek to ensure that CPD benefits the service user. Identify service user(s) in the con- text of mentorship CPD; it is likely to be the student(s), but also the department, education manager or higher education institution could be considered (section 3).

Standards 3 and 4 are the most critical and indepth part of the profile and form section 3 of the HCPC profile template. This part demonstrates how the CPD has been of benefit to an individual and others. It is the value of the activities that counts, not so much what has been done, but what the experience, and what you have learnt, has done to develop a professional.

Standard 5: On request, present a written profile, which must be a person's own work and supported by evidence, explaining how they have met the standards for CPD. From a list of CPD activities select 3 or 4 samples to discuss in their profile, one of which could be their mentorship CPD. Authenticity of this will be assessed and evidence of the activities need to be provided. For example, include a mentorship certificate of achievement, student feedback (anonymous), literature critique, appraisal excerpt, peer evaluation or personal reflection.

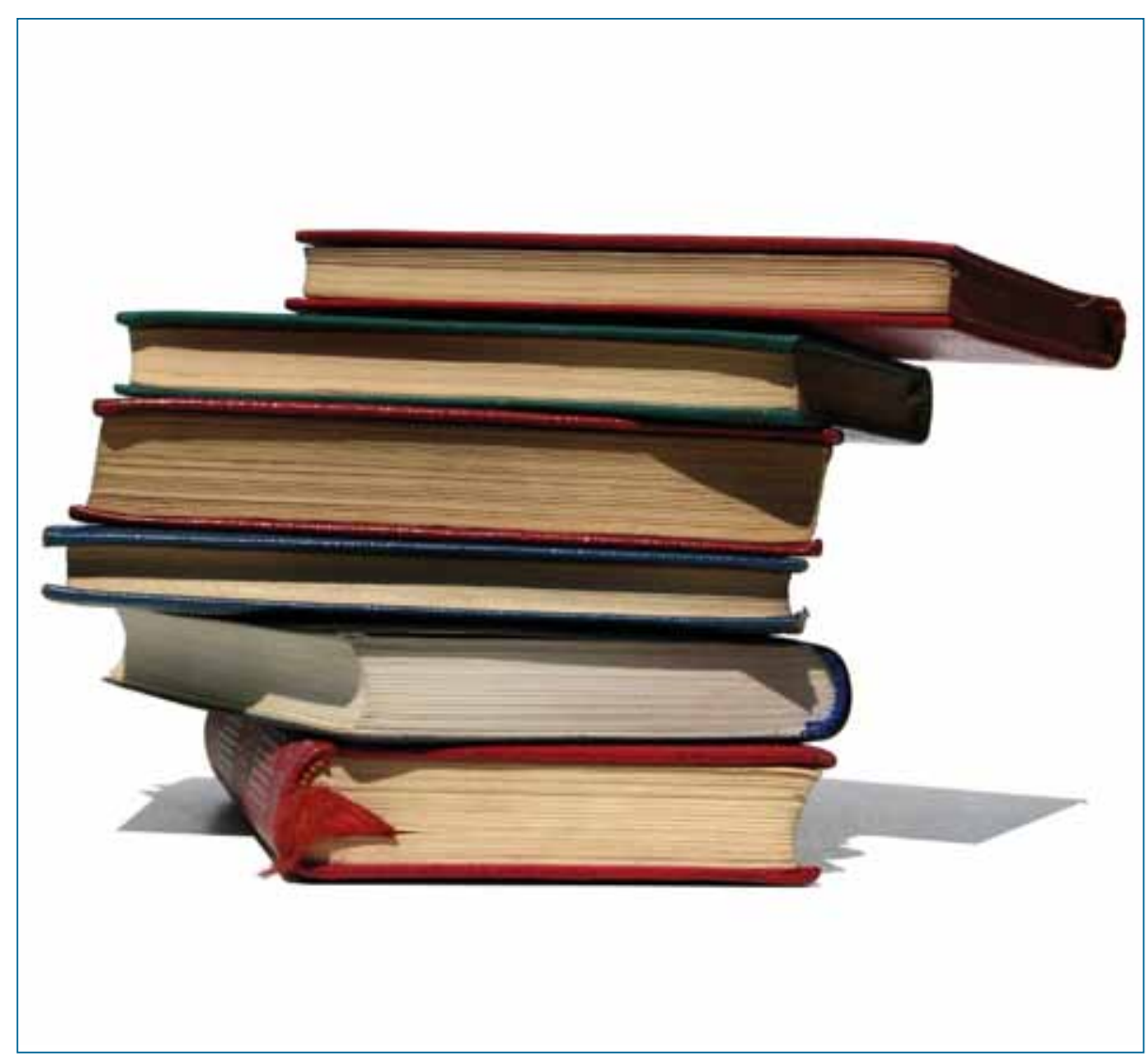

CPD focuses on career development, can demonstrate a culture of lifelong learning and helps to articulate a commitment to self-development and transference to service users 


\section{CPD: Building on what we experience - Making it useful}

Don't Stop: Think about all your activities -

Indentify how you would do things differently in the future What have you achieved \& what still needs to be done? (This will help establish your fuure learning needs)

\section{Continue to review \& develop:}

(You - Practice - Treatment - Career - ANYTHING!)

What was the situation then?

what did you do?

What is the situation now?

what would you like the situation to be?

\section{Ensure that you document your learning to meet} standard1!

Who uses your service or information i.e. the service user? (Student - staff - Manager - Patient - Profession) How will they benefit from your learning or activities? What evidence can you produce to support this?

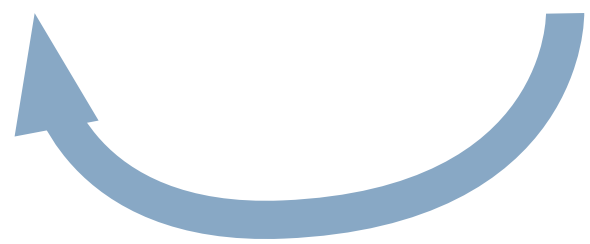

\section{Start:}

What activity did you engage in? describe what happened: What were the key themes or issues? Was it a range of activities? If not what type of activity?

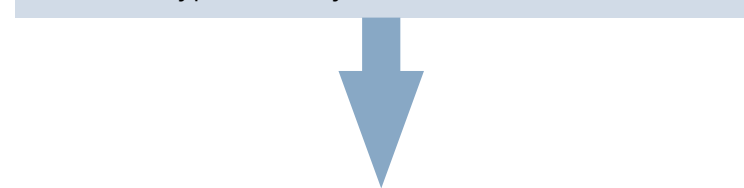

What did you learn?

What was new? What was old and less useful? Has this altered your view?

Will this alter your future decision-making?

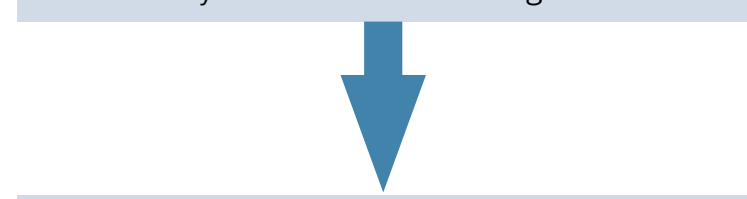

How will this activity enhance in quality of your work? How can you make new knowledge? will it enhance the delivery of your service?

The Harper and Joyce Model of CPD reflection, 2012, Adapted from John's model of reflection (1994)

Your reflection on key Study Day learning points:

apply the above cycle to the day's activities \& record your thoughts on this certificate

\section{Application to practice:}

How will this effect the way your work/develop - What benefit / improvements do you hope to achieve?
Attendee Signature:
Date:

When completed - keep as contributory evidence of your development planning and CPD activity. 


\section{A note about evidence}

Certificates are often used as proof of CPD. A cautionary word about certificates is that they are useful to prove that a person was at a specific location at a given time. They rarely prove that what was learnt was specified and they do not in themselves prove CPD activity. Sometimes it can be difficult to think back to a certified course and match learning to the CPD standards. This can result in a CPD activity that is very easy to evidence (certificate), but can prove troublesome when it comes to trying to prove that it has been of any benefit to a health professional or service users. One way to ensure that certified learning is captured appropriately is to reflect correctly on the learning that took place. Reflection is a very powerful and personal tool that allows the opportunity to contextualise a learning event and organise thoughts that consider usefulness of the event and next steps to be taken. Reflection is often used for informal learning events and is something that professionals do many times a day. Harper and Joyce (2008) developed and have since refined (Joyce and Harper, 2012) a reflective tool that can be used with any certificate attained (Figure 1). If this reflective cycle is followed while the certified learning event is still fresh in the mind it can assist with developing meaning and adding depth to that learning event while also affording strong evidence to support a CPD claim.

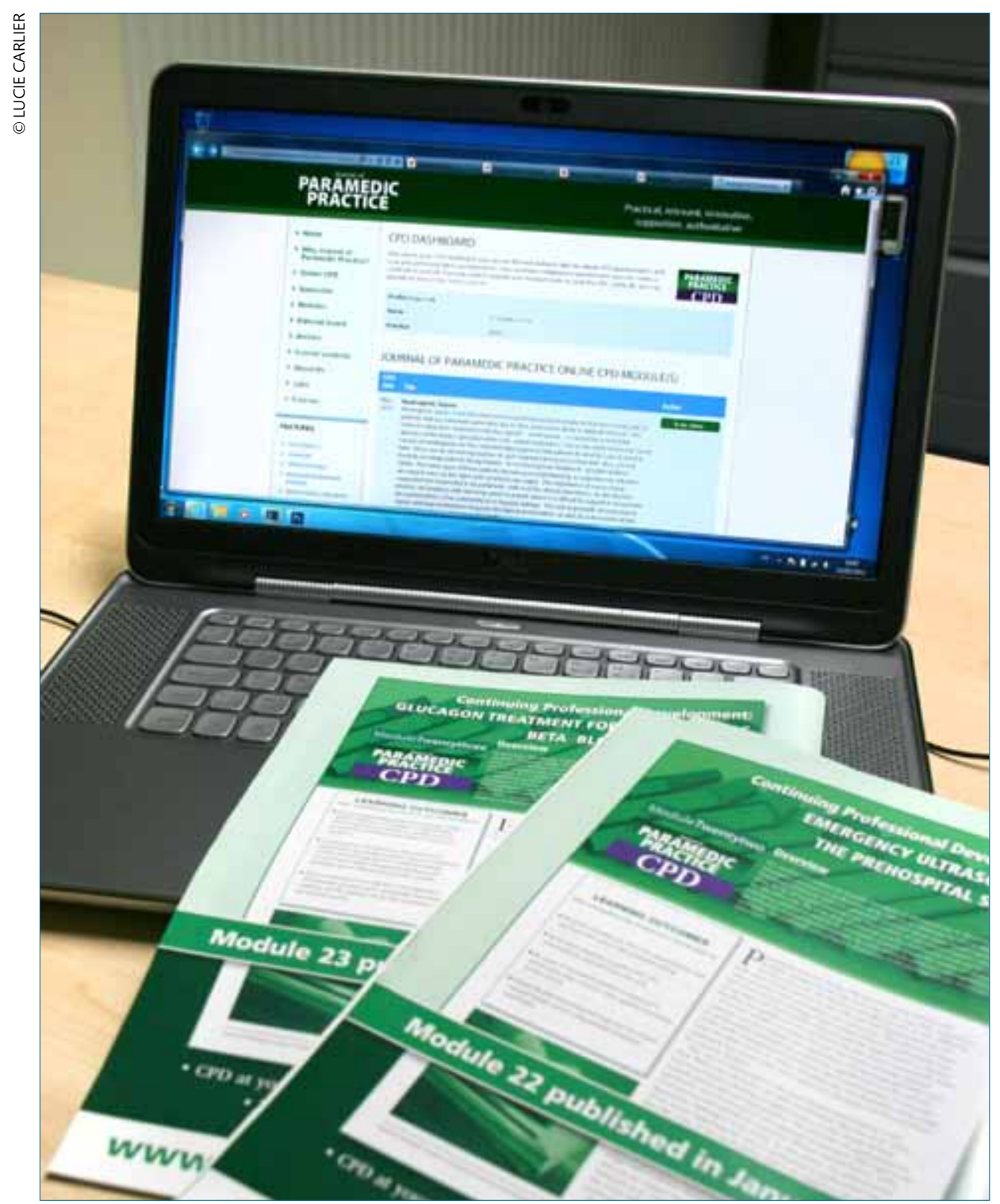

CPD is an investment in an individual; it is a way to manage their own learning and growth and can ensure that they turn the regulator's standards for accountable practice into a valuable tool

\section{Key points}

- Don't panic! CPD is easy and is probably already undertaken without formally managing or capturing the data

- Use CPD as a method of demonstrating adherence to HCPC standards and to guide professional development within the workplace as part of lifelong learning

- Record activities little and often and seek a range of activities

- Reflect on how activities will benefit the individual and their service users

- Always try and reflect on certified learning as this will provide meaning when the time comes to use it

\section{Conclusion}

CPD is an investment in an individual; it is a way to manage their own learning and growth and can ensure that they turn the regulator's standards for accountable practice into a valuable tool. An ODP has a responsibility to keep their skills and knowledge up-to-date in all areas of practice. This article has identified the statutory and professional drivers for CPD. It has discussed CPD context, as well as analysing lifelong learning and how an ODP might decide to manage their CPD. Generating the evidence to demonstrate CPD is a useful activity to undertake and can be used within the professional workplace as a measure of continual development and as a guide to future directions and aspirations. Finally, readers don't panic. If an ODP has not started, begin as soon as possible to allow control their professional future.

ODP

Conflict of interest: none

\section{References}

Coeffield F, ed (2000) Differing Visions of a Learning Society (Volume 2). Policy Press, Bristol

Department of Health (2002) Demonstrating competence through cpd: allied health professions report. http:// tinyurl.com/phdzdtn (accessed 14 July 2014)

Ellis E, Nolan M (2004) Illuminating continuing professional education: Unpacking the black box. Int J Nurs Stud 42: 97-106

Harper M, Joyce P (2008) CPD Countdown - are you ready? Introducing the Harper and Joyce model of reflection. CODP Conference, Fontwell, May 2008

Health and Care Professions Council (2012) Your Guide to our Standards for Continuing Professional Development. HCPC, London

Joyce P, Harper M. (2012) CPD Master Class. CODP Professional Study Day, London, 21 June 2012 